\title{
Preoperative Nomogram Predicts Non-Home Discharge in Patients Undergoing Pancreatoduodenectomy
}

\author{
Katelyn F. Flick ${ }^{\mathrm{a}}$, Chris M. Sublette ${ }^{\mathrm{g}}$, Thomas K. Maatman ${ }^{\mathrm{a}}$, Cameron L. Colgate, \\ Michele T. Yip-Schneider ${ }^{\mathrm{a}, \mathrm{d}-\mathrm{f}}$, Mazhar Soufi ${ }^{\mathrm{a}}$, Eugene P. Ceppa ${ }^{\mathrm{a}, \mathrm{f}}$, Michael G. House ${ }^{\mathrm{a}}$, \\ Nicholas J. Zyromski ${ }^{\mathrm{a}}$, Attila Nakeeb ${ }^{\mathrm{a}}$, C. Max Schmidt ${ }^{\mathrm{a}, \mathrm{b}, \mathrm{d}-\mathrm{f}}$
}

Departments of ${ }^{\mathrm{a}}$ Surgery, ${ }^{\mathrm{b} B i o c h e m i s t r y} /$ Molecular Biology, ${ }^{\mathrm{c}} \mathrm{Center}$ for Outcomes Research in Surgery, Indiana University School of Medicine, Indianapolis, IN; ${ }^{\mathrm{d} W a l t h e r ~ O n c o l o g y ~ C e n t e r, ~}$ ${ }^{\mathrm{e}}$ Indiana University Simon Cancer Center, Indiana University Health Pancreatic Cyst and Cancer Early Detection Center, Indianapolis, IN, ${ }^{\mathrm{g}}$ Indiana University School of Medicine, Indianapolis, IN

Twitter:@MaChHous (MG House), @maatman_tom (TK Maatman)

\section{Corresponding Author:}

C. Max Schmidt, MD, PhD, MBA, FACS

Department of Surgery, Biochemistry \& Molecular Biology

Indiana University School of Medicine

545 Barnhill Drive, Emerson Hall 129

Indianapolis, IN 46202

maxschmi@iupui.edu | www.pancyst.org

Office 317.948.8358 | Cell 317.372.9011 | Fax 317.274.0241

This manuscript includes data that were presented at the 2020 annual meeting of the AmericasHepato-Pancreato-biliary Association (March 5-8, 2020).

Author contribution: KFF, CMS, TKM, and MS were involved in the conception of the project, acquisition, analysis, and interpretation of data, and drafting and revising the work. CMS serves as the mentor and corresponding author for the work and was involved in the conception, interpretation, revision, and final approval of the work; CMS agrees to be accountable for the work. CLC, MTY-S, EPC, MGH, NJZ, AN, and CMS, and were involved in the conception of the project, revision of the work, and final approval.

Category: Original Article

Conflicts of interest: None declared

Financial support: None

Short Title: Nomogram for Discharge Location.

This is the author's manuscript of the article published in final edited form as:

Flick, K. F., Schmidt, C. M., Colgate, C. L., Yip-Schneider, M. T., Sublette, C. M., Maatman, T. K., Soufi, M., Ceppa, E. P., House, M. G., Zyromski, N. J., \& Nakeeb, A. (2021). Preoperative Nomogram Predicts Non-home Discharge in Patients Undergoing Pancreatoduodenectomy. Journal of Gastrointestinal Surgery, 25(5), 1253-1260. https://doi.org/10.1007/s11605-020-04689-1 


\section{ABSTRACT \\ Background:}

In patients undergoing pancreatoduodenectomy, non-home discharge is common and often results in an unnecessary delay in hospital discharge. This study aimed to develop and validate a preoperative prediction model to identify patients with a high likelihood of non-home discharge following pancreatoduodenectomy.

\section{Methods:}

Patients undergoing pancreatoduodenectomy from 2013-2018 were identified using an institutional database. Patients were categorized according to discharge location (Home vs. NonHome). Preoperative risk factors, including social determinants of health associated with nonhome discharge, were identified using Pearson's chi-squared test and then included in a multiple logistic regression model. A training cohort composed of $80 \%$ of the sampled patients was used to create the prediction model, and validation carried out using the remaining $20 \%$. Statistical significance was defined as $P<0.05$.

\section{Results:}

766 pancreatoduodenectomy patients met the study criteria for inclusion in the analysis (nonhome: 126; home: 640). Independent predictors of non-home discharge on multivariable analysis were age, marital status, mental health diagnosis, functional health status, dyspnea, and chronic obstructive pulmonary disease. The prediction model was then used to generate a nomogram to predict likelihood of non-home discharge. The training and validation cohorts demonstrated comparable performances with an identical area under the curve $(0.81)$ and an accuracy of $84 \%$.

\section{Conclusion:}

A prediction model to reliably assess the likelihood of non-home discharge after pancreatoduodenectomy was developed and validated in the present study.

Keywords: Nomogram, Pancreatoduodenectomy, Patient Discharge 


\section{Introduction}

Pancreatoduodenectomy (PD) is performed for benign and malignant conditions of the duodenum, distal bile duct, and head of the pancreas. An increasing number of PD are performed annually, likely the result of expanding indications for PD, increasing incidence of pancreatic cancer, and older age no longer associated with prohibitive risk for $\mathrm{PD}[1-4]$. Greater experience and improved postoperative care after PD have reduced postoperative mortality to $1-5 \%[5-8]$. Despite this, perioperative morbidity remains high (up to $40 \%$ ), and recovery after PD may be slow[5-10]. Improving the effectiveness of resource utilization during postoperative care is essential to providing efficient, high-quality, personalized care to patients undergoing PD.

Recent innovations in postoperative care aim to decrease postoperative complications, hospital length of stay (LOS), and discharge to subacute or rehabilitation facilities. Prolonged LOS and non-home discharge (NHD) after PD are often associated with postoperative complications $[11,12]$. However, preoperative baseline health also plays an important role in postoperative recovery. Preoperative identification of patients likely to require NHD may allow the upfront direction of hospital resources to high-risk patients, thus preventing delays in hospital discharge and increasing the efficiency of care.

We hypothesized that clinical metrics identified at the preoperative visit could be used to assess the likelihood of NHD after PD. Of particular interest were preoperative risk factors, including social determinants of health. The aim of this study was to develop and validate a preoperative model to predict patients likely to require non-home discharge after pancreatoduodenectomy. 


\section{Materials and Methods}

\section{Patient Population}

A retrospective review of a prospectively maintained American College of SurgeonsNational Surgical Quality Improvement Program (ACS-NSQIP) institutional database was performed to identify patients undergoing open PD at Indiana University (IU) Health University Hospital between 2013-2018. Inclusion criteria were patients greater than 18 years of age and those undergoing open PD for any disease diagnosis. Patients were excluded if they had a documented preoperative infection, open wound, acute renal failure, dialysis, disseminated cancer, preoperative transfusion, or if death occurred prior to discharge. The remaining patients were categorized according to the discharge location. The IU Institutional Review Board approved the conduct of this study, and data storage was compliant with the Health Insurance Portability and Accountability Act.

\section{Clinical Data}

All monitored ASC-NSQIP variables were evaluated, and the clinical database was augmented through individual patient medical record review. Preoperative diagnosis of mental disease (defined below), and marital status were recorded in addition to the standardized ACSNSQIP variables. Only inpatient complications were included and categorized according to the system. The primary outcome was discharge location, categorized per the NSQIP dictionary, and outlined below. Secondary endpoints included monitored postoperative ACS-NSQIP outcomes. 


\section{Definitions}

A mental disease diagnosis was defined as a preoperative diagnosis of psychiatric illness (anxiety, depression, schizophrenia, or bipolar disorder) treated with medication.

Discharge location was classified as Home vs. Non-Home defined as follows:

1. Home: Place of residence prior to admission. Home health care available to those who qualify.

a. Home health care provides intermittent care to patients at home. Available services include physical, occupational, and speech therapy, in addition to medical social work visits. To qualify, patient must be physically unable to leave their home, or in the process of leaving home put themselves in harm's way[13].

2. Non-Home: Skilled care facility (transitional care unit, subacute hospital, ventilator bed, skilled nursing facility/home), an unskilled facility (nursing home), acute care facility, rehab or assisted living.

a. Skilled care facilities offer 24-hour skilled nursing and personal patient care, while also providing rehabilitation services. In order to qualify for discharge to such a facility, the patient must be medically stable and require the care of skilled, licensed professionals. Examples of such care include complex wound care or deconditioning that does not enable the patient to tolerate at home therapy and/or assistance[13].

\section{Statistics}

Differences in preoperative variables between HD and NHD patients were assessed using Chi-squared tests and Fisher's exact tests. Then, all preoperative variables with group differences significant at the $\mathrm{P}<0.1$ level were included in a multiple logistic regression model predicting 
NHD. Finally, a predictive model for NHD was developed by running a multiple logistic regression containing only preoperative variables significant at the $p<0.1$ level in the prior step. The final predictive model was generated using $80 \%$ of complete cases, and then its accuracy, AUC, sensitivity, and specificity was tested using the remaining $20 \%$ of complete cases. A nomogram of the final predictive model was then created by entering the results of a regression into the package's nomogram function ${ }^{[14]}$. The biostatistical analysis was performed by the Indiana University Center for Outcomes Research in Surgery (CORES) using R, version 3.5.0 (Vienna, Austria).

\section{Results}

In the present study, 766 patients underwent PD between 2013-2018 and met inclusion criteria. Home discharge was more frequent $(n=640,84 \%)$ than NHD $(n=126,16 \%)$. The most frequent destination of NHD was a skilled care facility $(\mathrm{n}=118,94 \%)$ followed by a rehabilitation facility $(\mathrm{n}=8,6 \%)$. The mean $(\mathrm{SD})$ age of all patients was 65.2 years $(+/-12.5)$, with $384(50 \%)$ represented by women. Within the overall cohort, $60 \%$ had a malignancy, and the most common was pancreatic ductal adenocarcinoma $(n=381,50 \%)$. Benign disease was present in $40 \%$ of patients, with chronic pancreatitis ( $\mathrm{n}=213,28 \%)$ being the most common.

Postoperative complications were not included in developing the nomogram but were monitored. Of the 766 patients, 256 (33\%) patients experienced a postoperative complication. Complications were more frequent in the NHD cohort (69/126, 55\%) when compared to the Home cohort (187/640, 29\%), P $<0.001$. In the NHD cohort, pulmonary complications, cardiovascular complications, renal complications, and surgical site infection occurred more frequently than in patients discharged to home, Table 1. Despite the significant differences in the incidence of postoperative complications, readmission rates were similar between the two 
groups, HD 102(16\%) vs. NHD 19(15\%), $\mathrm{P}=0.90 .14(2 \%)$ patients required operative takeback (HD $8(1.2 \%)$ vs NHD $6(5 \%)), 12$ of which were related to the primary procedure $(86 \%)$. Of those that were initially discharged home and readmitted, 10(10\%) required subsequent discharge to a facility (NHD) and 1(1\%) died during the readmission.

On multivariable analysis of only preoperative variables, significant independent predictors of NHD included advanced age, marital status (single), presence of a mental health diagnosis, dependent functional health status (FHS), dyspnea, and chronic obstructive pulmonary disease (COPD), Table 2. Odds ratios (with 95\% confidence intervals, CI) of these risk factors are shown in Figure 1. Other important metrics investigated that were not found to be statistically significant included distance from home to hospital and insurance status (private vs public). Distance from home was categorized as greater or less than 100miles (HD 246(38\%) vs. NHD 41(33\%), $\mathrm{P}=0.2112$ ), while insurance status was also similar (Private vs Public insurance $\mathrm{OR}(95 \% \mathrm{CI}) 1.64(0.97-2.76), \mathrm{P}=0.061)$

Using this prediction model, a nomogram was generated to predict a patient's likelihood of NHD, Figure 2. Each patient receives points based on the presence of these comorbidities. The total points are then converted to a probability of NHD. Both the training and validation cohorts, corresponding to 80 and $20 \%$ of the available data respectively, demonstrated comparable performances with an identical AUC (0.81) and an accuracy of $84 \%$, Figure 3.

\section{Discussion}

Pancreatoduodenectomy is a complex surgery that often requires the expertise and coordination of multiple specialties and supportive care teams. This study developed and validated a reliable preoperative nomogram to predict NHD following PD. The preoperative 
variables most strongly associated with NHD were age, marital status, mental health, functional health status, dyspnea, and COPD. Although age, functional status, dyspnea, and COPD were previously described in nomograms predictive of NHD after PD[15, 11], the present model importantly includes social determinants of health that were not evaluated in prior studies. This nomogram will facilitate discussions with patients in the preoperative clinic to set realistic expectations that may increase patient satisfaction by reducing the number of unanticipated outcomes. Additionally, this predictive model has the potential to aid in discharge planning by identifying those patients that will benefit most from additional hospital resources.

Similar studies identifying predictors of discharge destination have been performed in other surgical subspecialties as well, including orthopedic surgery[16, 17] and gynecological surgery[18]. Age was the most significant contributing component of our predictive model. Among the elderly, NHD was found to be necessary for up to $12-15 \%$ of patients[19]. Unlike the ACS-NSQIP calculator, which limits age to a categorical variable, the nomogram developed in this study uses age as a continuous variable. This increases the precision of our predictive model and allows for more individualized risk prediction. Even in elderly patients without complications, post-acute care services are often still required, most commonly for deconditioning and rehabilitation to return to baseline health[20].

Preoperative functional status plays a vital role in postoperative outcomes as well. Over $50 \%$ of patients considered to be partially or totally functional dependent prior to surgery will discharge to a destination other than home independent of postoperative complications [21]. Irrespective of home support, patients requiring postoperative care beyond their already significant baseline needs are often a substantial burden on friends and family. Another important factor determining discharge destination is marital status. In a study evaluating 
discharge location in patients that lived alone, $38 \%$ were discovered to require discharge to a subacute nursing facility[22]. Having support at home is vital to ensure a safe discharge and optimal patient recovery in the acute postoperative setting. Physical and occupational therapy teams often evaluate the physical abilities of a patient prior to hospital discharge, taking into account the marital status and available support. Findings of the current study are supported by a recent report from Pandey et al that associated marital status with decreased SNF use[23]. While non-modifiable, it is an important demographic factor to be cognizant of when caring for a patient.

An estimated 34.2 million adults in the United States currently smoke cigarettes $^{[24]}$, and more than 16 million Americans live with a smoking-related disease[25]. COPD represents a debilitating disease associated with significant morbidity and is the fourth leading cause of death worldwide[26]. The impact of COPD on postoperative outcomes was previously investigated by Gupta et al on 22,576 surgical patients, finding COPD to be associated with extended hospital LOS, increased morbidity, and 30-day mortality over 6\%[27]. This is consistent with our data as COPD is deemed to be a significant contributor to NHD. Dyspnea was also associated with an increased likelihood of NHD after PD. While this is the only subjective parameter included in the predictive model, it is often a symptom of a more serious underlying process such as severe COPD, heart failure, or reduced functional capacity.

Mental health is becoming an increasingly discussed topic, clinically diagnosed in 1 in 5 adults in the United States (46.6 million in 2017)[28]. The impact of this diagnosis reaches beyond emotional and mental health, potentially affecting a patient's physical health. Kugelman et al found that psychiatric illness played a crucial role in pain scores immediately after surgery and was an independent predictor of worse functional outcomes[29]. Preoperative mental health 
has been shown to impact patients undergoing outpatient surgery. Those with poorer baseline mental health had increased unfavorable symptoms and discomfort reported in the postoperative setting ${ }^{[30]}$. In the current study, the contribution of a mental disease diagnosis toward overall risk on the nomogram was greater than COPD and dyspnea, suggesting that mental health should be considered and addressed in the perioperative setting. While it may not be feasible to optimize mental health before surgery completely, attention to this issue is essential to providing appropriate care. A nomogram inclusive of mental illness diagnoses incorporates this comorbidity into the routine operative counseling and may allow for an opportunity to improve the perioperative care by planning ahead.

Although postoperative complications were not incorporated within the nomogram, they were included to further compare the two groups. As expected, those requiring more extensive care after discharge did experience complications more frequently, however when the population is evaluated as a whole, complication rates are well within normal, accepted rates within the literature (delayed gastric emptying 13\%, pancreatic fistula 13\%, and incisional surgical site infection 12\%). In addition, previous studies from our institution have reflected on surgical practices that highlight these postoperative complications and measures taken to reduce them[3133]. This suggests that the patient cohort is 'higher risk' as identified by the preoperative nomogram and less likely due to quality of surgical technique employed by the surgeons who all have high volume experience in hepato-pancreato-biliary surgery.

Discharge destination is a significant factor in patient outcomes. Patients that require NHD are more likely to have longer hospital LOS, and in this study, LOS was 7 days longer in the NHD patients. A study from as early as the 1980 s attributed $12 \%$ of inpatient hospital days to waiting for acceptance to post-discharge facilities ${ }^{[34]}$. Furthermore, a study by Srivastava et al 
reported that over $20 \%$ of discharge delays are secondary to poor planning ${ }^{[35]}$. These excess inpatient days are an inefficient use of hospital resources that increase hospital costs and decrease bed availability for higher acuity patients. One way to reduce these hospital days is to anticipate a need for rehab or an acute care facility. Predicting discharge destination has been shown to improve discharge efficiency, increase patient satisfaction, and reduce unnecessary utilization of hospital resources by decreasing LOS and consequently producing cost savings[36, 37]. The national average daily expense for a private room in a nursing home is about $\$ 275[38]$ in contrast to an in-patient hospital day of close to $\$ 4,000$ [39]. Thus, any delay in discharge due to a prolonged wait for acceptance to a facility places a substantial financial burden on the patient which is usually born by the hospital. A 2001 study found that by utilizing a facility, the total cost of major head and neck surgical cases could be reduced by about $15 \%[40]$.

The use of a nomogram such as the one created in this study equips the healthcare team prospectively with predictive tools to help target patients to an appropriate discharge location. Currently, the process at our institution involves a multidisciplinary meeting every day to assess patient status and outlook to determine discharge needs. However, no planning or application for insurance approval begins until the surgical team states an estimated plan for discharge. With this initial assessment, its prediction can guide earlier utilization of these resources and initiate the discharge process earlier on, potentially reducing the unnecessary number of days some patients spend awaiting acceptance while medically ready to leave. Moreover, this can be used at the initial preoperative office visit to evaluate patients. Ideally, patients desire to know their expected discharge disposition before surgery to allow time for adequate planning[41]. This study is novel and improved from a previous nomograms[11] in patients undergoing PD; namely, 
by the inclusion of social determinants of health variables, known to be important predictors of discharge destination[23, 42, 43].

Aside from the retrospective nature of this study, an additional limitation is the absence of information regarding the availability of family or home support for patients. The status of home support beyond marital status is something not routinely recorded within the preoperative evaluation. As a result, this additional personal information is lacking and did not factor into developing the present nomogram. The importance of marital status does indicate the impact that a support system has on dictating discharge location and a separate study should be conducted see if this could be broadened to include support other than husband or wife. An addition limitation includes patient exclusions that were made in an attempt to make the cohort as homogeneous as possible. Thus, this model may be of limited use for sicker patients (those excluded) undergoing urgent/emergent surgery. This nomogram may help identify patients that may otherwise not be recognized as high risk for NHD.

\section{Conclusion}

A prediction model to reliably assess the likelihood of NHD after PD was developed and validated in the present study. The resulting nomogram may enable hospital resources to be directed early towards those requiring a NHD, streamlining the transition and early acceptance to a facility. Our nomogram is the first to include social determinants of health variables within the model, incorporating important factors that have a critical impact but are often overlooked. 


\section{References:}

1. Griffin JF, Poruk KE, Wolfgang CL. Pancreatic cancer surgery: past, present, and future. Chin J Cancer Res. 2015;27(4):332-48. doi:10.3978/j.issn.1000-9604.2015.06.07.

2. Ryan CE, Wood TW, Ross SB, Smart AE, Sukharamwala PB, Rosemurgy AS. Pancreaticoduodenectomy in Florida: do 20-year trends document the salutary benefits of centralization of care? HPB (Oxford). 2015;17(9):832-8. doi:10.1111/hpb.12467.

3. Rahib L, Smith BD, Aizenberg R, Rosenzweig AB, Fleshman JM, Matrisian LM. Projecting cancer incidence and deaths to 2030: the unexpected burden of thyroid, liver, and pancreas cancers in the United States. Cancer Res. 2014;74(11):2913-21. doi:10.1158/0008-5472.CAN-14-0155.

4. Kim SY, Weinberg L, Christophi C, Nikfarjam M. The outcomes of pancreaticoduodenectomy in patients aged 80 or older: a systematic review and meta-analysis. HPB (Oxford). 2017;19(6):47582.

5. Schmidt C, Powell E, Yiannoutsos C, Howard T, Wiebke E, Wiesenauer C et al. Pancreaticoduodenectomy: a 20-year experience in 516 patients. Arch Surg. 2004;139(7):71825; discussion 25-7.

6. Cameron JL, He J. Two thousand consecutive pancreaticoduodenectomies. J Am Coll Surg. 2015;220(4):530-6. doi:10.1016/j.jamcollsurg.2014.12.031.

7. Maatman TK, Weber DJ, Timsina LR, Qureshi B, Ceppa EP, Nakeeb A et al. Antibiotic irrigation during pancreatoduodenectomy to prevent infection and pancreatic fistula: A randomized controlled clinical trial. Surgery. 2019;166(4):469-75. doi:10.1016/j.surg.2019.05.053.

8. Schmidt CM, Turrini O, Parikh P, House MG, Zyromski N, Nakeeb A et al. Effect of hospital volume, surgeon experience, and surgeon volume on patient outcomes after pancreaticoduodenectomy: a single-institution experience. Arch Surg. 2010;145(7):634-40.

9. Maatman TK, Weber DJ, Qureshi B, Ceppa EP, Nakeeb A, Schmidt CM et al. Does the Microbiology of Bactibilia Drive Postoperative Complications After Pancreatoduodenectomy? J Gastrointest Surg. 2019; [Epub ahead of print].

10. Torphy RJ, Chapman BC, Friedman C, Nguyen C, Bartsch CG, Meguid C et al. Quality of Life Following Major Laparoscopic or Open Pancreatic Resection. Ann Surg Oncol. 2019;26(9):298593. doi:10.1245/s10434-019-07449-x.

11. Nassour I, Wang SC, Christie A, Mokdad AA, Porembka MR, Choti MA et al. Nomogram to predict non-home discharge following pancreaticoduodenectomy in a national cohort of patients. HPB : the official journal of the International Hepato Pancreato Biliary Association. 2017;19(12):103745. doi:10.1016/j.hpb.2017.07.011.

12. Xourafas D, Pawlik TM, Cloyd JM. Independent Predictors of Increased Operative Time and Hospital Length of Stay Are Consistent Across Different Surgical Approaches to Pancreatoduodenectomy. J Gastrointest Surg. 2018;22(11):1911-9. doi:10.1007/s11605-0183834-6.

13. 2020 Case Management Study Guide. In: Levels of Care. 2020. https://casemanagementstudyguide.com/ccm-knowledge-domains/healthcare-managementdelivery/levels-of-care/. Accessed April 28, 20202020.

14. Jr FEH. rms: Regression Modeling Strategies. R package. 2019. http://biostat.mc.vanderbilt.edu/rms. 2019.

15. Mahvi DA, Pak LM, Urman RD, Gold JS, Whang EE. Discharge destination following pancreaticoduodenectomy: A NSQIP analysis of predictive factors and post-discharge outcomes. American journal of surgery. 2019;218(2):342-8. doi:10.1016/j.amjsurg.2018.11.043. 
16. Di Capua J, Somani S, Kim JS, Lee NJ, Kothari P, Phan K et al. Predictors for Patient Discharge Destination After Elective Anterior Cervical Discectomy and Fusion. Spine (Phila Pa 1976). 2017;42(20):1538-44. doi:10.1097/brs.0000000000002140.

17. Schwarzkopf R, Ho J, Quinn JR, Snir N, Mukamel D. Factors Influencing Discharge Destination After Total Knee Arthroplasty: A Database Analysis. Geriatr Orthop Surg Rehabil. 2016;7(2):95-9. doi:10.1177/2151458516645635.

18. Penn CA, Kamdar NS, Morgan DM, Spencer RJ, Uppal S. Preoperatively predicting non-home discharge after surgery for gynecologic malignancy. Gynecol Oncol. 2019;152(2):293-7. doi:10.1016/j.ygyno.2018.11.029.

19. Sacks GD, Lawson EH, Dawes AJ, Gibbons MM, Zingmond DS, Ko CY. Which Patients Require More Care after Hospital Discharge? An Analysis of Post-Acute Care Use among Elderly Patients Undergoing Elective Surgery. J Am Coll Surg. 2015;220(6):1113-21.e2. doi:10.1016/j.jamcollsurg.2015.02.029.

20. Li LT, Barden GM, Balentine CJ, Orcutt ST, Naik AD, Artinyan A et al. Postoperative transitional care needs in the elderly: an outcome of recovery associated with worse long-term survival. Ann Surg. 2015;261(4):695-701. doi:10.1097/sla.0000000000000673.

21. Balentine CJ, Naik AD, Berger DH, Chen H, Anaya DA, Kennedy GD. Postacute Care After Major Abdominal Surgery in Elderly Patients: Intersection of Age, Functional Status, and Postoperative Complications. JAMA surgery. 2016;151(8):759-66. doi:10.1001/jamasurg.2016.0717.

22. Fang C, Lim SJ, Tybor DJ, Martin J, Pevear ME, Smith EL. Factors Determining Home Versus Rehabilitation Discharge Following Primary Total Joint Arthroplasty for Patients Who Live Alone. Geriatrics (Basel). 2020;5(1). doi:10.3390/geriatrics5010007.

23. Pandey KR, Yang F, Cagney KA, Smieliauskas F, Meltzer DO, Ruhnke GW. The impact of marital status on health care utilization among Medicare beneficiaries. Medicine. 2019;98(12):e14871. doi:10.1097/md.0000000000014871.

24. MeLisa R. Creamer TWW, Stephen Babb, Karen Cullen, hannah Day, Gordon Willis, Ahmed Jamal, Linda Neff. Tobacco Product Use and Cessation Indicators Among Adults-United States 2018. Center for Disease Control and Prevention. 2019;68:1013-9. doi:

http://dx.doi.org/10.15585/mmwr.mm6845a2external icon.

25. Surgeon General's Report: The Health Consequences of Smoking-50 Years Progress. In: Smoking and Tobacco Use. CDC. 2014. https://www.cdc.gov/tobacco/data statistics/sgr/50thanniversary/index.htm. Accessed February 26. 20202020.

26. World Health Statistics 2015. Geneva. Switzerland: World Health Organization; 2015.

27. Gupta H, Ramanan B, Gupta PK, Fang X, Polich A, Modrykamien A et al. Impact of COPD on postoperative outcomes: results from a national database. Chest. 2013;143(6):1599-606. doi:10.1378/chest.12-1499.

28. Mental Health Information. In: Statistics. National Institute of Mental Health. 2020. https://www.nimh.nih.gov/health/statistics/mental-illness.shtml. Accessed February 26, 2020 2020.

29. Kugelman D, Qatu A, Haglin J, Konda S, Egol K. Impact of Psychiatric Illness on Outcomes After Operatively Managed Tibial Plateau Fractures (OTA-41). J Orthop Trauma. 2018;32(6):e221-e5. doi:10.1097/bot.0000000000001138.

30. Nilsson U, Dahlberg K, Jaensson M. Low Preoperative Mental and Physical Health is Associated with Poorer Postoperative Recovery in Patients Undergoing Day Surgery: A Secondary Analysis from a Randomized Controlled Study. World J Surg. 2019;43(8):1949-56. doi:10.1007/s00268019-04995-z. 
31. Beane JD, House MG, Miller A, Nakeeb A, Schmidt CM, Zyromski NJ et al. Optimal management of delayed gastric emptying after pancreatectomy: an analysis of 1,089 patients. Surgery. 2014;156(4):939-46. doi:10.1016/j.surg.2014.06.024.

32. Flick KF, Simpson RE, Soufi M, Fennerty ML, Yip-Schneider MT, Colgate CL et al. Comparison of skin closure techniques in patients undergoing open pancreaticoduodenectomy: A single center experience. American journal of surgery. 2020. doi:10.1016/j.amjsurg.2020.02.023.

33. Ceppa EP, Pitt HA, House MG, Kilbane EM, Nakeeb A, Schmidt CM et al. Reducing surgical site infections in hepatopancreatobiliary surgery. HPB : the official journal of the International Hepato Pancreato Biliary Association. 2013;15(5):384-91. doi:10.1111/j.14772574.2012.00604.x.

34. Hospital's SNF placement initiative improves efficiency, speeds discharge. Hosp Case Manag. 2003;11(12):177-9.

35. Srivastava R, Stone BL, Patel R, Swenson M, Davies A, Maloney CG et al. Delays in discharge in a tertiary care pediatric hospital. J Hosp Med. 2009;4(8):481-5. doi:10.1002/jhm.490.

36. Tong MZ, Pattakos G, He J, Rajeswaran J, Kattan MW, Barsoum WK et al. Sequentially Updated Discharge Model for Optimizing Hospital Resource Use and Surgical Patients' Satisfaction. Ann Thorac Surg. 2015;100(6):2174-81. doi:10.1016/j.athoracsur.2015.05.090.

37. Barsoum WK, Murray TG, Klika AK, Green K, Miniaci SL, Wells BJ et al. Predicting patient discharge disposition after total joint arthroplasty in the United States. J Arthroplasty. 2010;25(6):885-92. doi:10.1016/j.arth.2009.06.022.

38. Nursing Homes. In: Nursing Home Costs. Senior Living. 2020. https://www.seniorliving.org/nursing-homes/costs/. Accessed February 26, 20202020.

39. Hospital and Surgery Costs. In: Medical Debt Advice. Debt.org. 2020. https://www.debt.org/medical/hospital-surgery-costs/. Accessed February 26, 20202020.

40. Seikaly H, Calhoun KH, Stonestreet JS, Rassekh CH, Driscoll BP, Averyt P. The impact of a skilled nursing facility on the cost of surgical treatment of major head and neck tumors. Arch Otolaryngol Head Neck Surg. 2001;127(9):1086-8. doi:10.1001/archotol.127.9.1086.

41. Lambert-Kerzner A, Ford KL, Hammermeister KE, Henderson WG, Bronsert MR, Meguid RA. Assessment of attitudes towards future implementation of the "Surgical Risk Preoperative Assessment System" (SURPAS) tool: a pilot survey among patients, surgeons, and hospital administrators. Patient Saf Surg. 2018;12:12. doi:10.1186/s13037-018-0159-z.

42. Kanaan SF, Yeh HW, Waitman RL, Burton DC, Arnold PM, Sharma NK. Predicting discharge placement and health care needs after lumbar spine laminectomy. J Allied Health. 2014;43(2):88-97.

43. McBride KE, Solomon MJ, Young JM, Steffens D, Lambert TJ, Glozier $N$ et al. Impact of serious mental illness on surgical patient outcomes. ANZ J Surg. 2018. doi:10.1111/ans.14508. 


\begin{tabular}{|l|c|c|c|}
\hline & $\begin{array}{l}\text { Home } \\
\text { Discharge } \\
\text { N (\%) }\end{array}$ & $\begin{array}{c}\text { Non-Home } \\
\text { Discharge } \\
\text { N (\%) }\end{array}$ & P Value \\
\hline Any Complication & $187(29.2)$ & $69(54.8)$ & $<\mathbf{0 . 0 0 1}$ \\
\hline Pulmonary Complication & $17(2.7)$ & $19(15.1)$ & $<\mathbf{0 . 0 0 1}$ \\
\hline Unplanned Intubation & $8(1.2)$ & $15(11.9)$ & $<\mathbf{0 . 0 0 1}$ \\
\hline Pneumonia & $10(1.6)$ & $10(7.9)$ & $<\mathbf{0 . 0 0 1}$ \\
\hline $\begin{array}{l}\text { Prolonged Ventilation } \\
\text { (>48hrs) }\end{array}$ & $5(0.8)$ & $12(9.5)$ & $<\mathbf{0 . 0 0 1}$ \\
\hline $\begin{array}{l}\text { Cardiovascular } \\
\text { Complication }\end{array}$ & $17(2.7)$ & $11(8.7)$ & $\mathbf{0 . 0 0 2}$ \\
\hline Myocardial Infarction & $5(0.8)$ & $4(3.2)$ & $\mathbf{0 . 0 4 4}$ \\
\hline Cerebral Vascular Accident & $0(0)$ & $1(0.8)$ & 0.2 \\
\hline Deep Venous Thrombosis & $7(1.1)$ & $7(5.6)$ & $\mathbf{0 . 0 0 3}$ \\
\hline Pulmonary Embolism & $5(0.8)$ & $2(1.6)$ & 0.6 \\
\hline Cardiac Arrest & $1(0.2)$ & $3(2.4)$ & $\mathbf{0 . 0 1 4}$ \\
\hline $\begin{array}{l}\text { Any Infectious } \\
\text { Complication }\end{array}$ & $79(12.3)$ & $29(23)$ & $\mathbf{0 . 0 0 2}$ \\
\hline Superficial Site Infection & $69(10.8)$ & $26(20.6)$ & $\mathbf{0 . 0 0 9}$ \\
\hline Clostridium difficile & $3(0.5)$ & $2(1.6)$ & 0.2 \\
\hline Sepsis & $25(3.9)$ & $8(6.3)$ & 0.2 \\
\hline Renal Complication & $6(0.9)$ & $12(9.5)$ & $<\mathbf{0 . 0 0 1}$ \\
\hline Urinary Tract Infection & $6(0.9)$ & $12(9.5)$ & $<\mathbf{0 . 0 0 1}$ \\
\hline Other & $125(19.5)$ & $49(38.9)$ & $<\mathbf{0 . 0 0 1}$ \\
\hline Pancreatic Fistula & $78(12.2)$ & $24(19.2)$ & $\mathbf{0 . 0 4 3}$ \\
\hline Delayed Gastric Emptying & $64(11.8)$ & $34(29.6)$ & $<\mathbf{0 . 0 0 1}$ \\
\hline Tabl Postoperative & & & \\
\hline
\end{tabular}

Table 1. Postoperative Complications According to Discharge Location Major Categories in Bold. 


\begin{tabular}{|l|l|l|l|}
\hline Factors & Home Discharge N(\%) & Non-home Discharge N(\%) & P value \\
\hline Age $>\mathbf{6 5}$ & $274(43)$ & $105(83)$ & $<0.0001$ \\
\hline Married & $430(67)$ & $56(44)$ & $<0.0001$ \\
\hline Mental Health Dx & $188(30)$ & $47(37)$ & 0.043 \\
\hline Dependent FHS & $3(1)$ & $5(4)$ & 0.018 \\
\hline Dyspnea & $44(7)$ & $17(14)$ & 0.011 \\
\hline COPD & $43(7)$ & $16(13)$ & 0.007 \\
\hline
\end{tabular}

Table 2. Multivariable analysis to Determine Risk Factors for Non-Home Discharge Abbreviations: Dx - diagnosis; FHS - functional health status; COPD - chronic obstructive pulmonary disorder

\section{Figure Legend}

Figure 1. Forest Plot depicting Odds Ratios (with 95\% Confidence Intervals) of Non-Home Discharge Among Each Risk Factor Abbreviations: Dx - diagnosis; FHS - functional health status; COPD - chronic obstructive pulmonary disorder

Figure 2. Nomogram to Predict Non-Home Discharge Abbreviations: COPD-Chronic obstructive pulmonary disease, Dx: Diagnosis, FHS: Functional health status, NHD: Non-home discharge

Figure 3. Receiver Operator Characteristic Curve of the Predictive Model for Non-Home Discharge Using the Validation Cohort Abbreviations: AUC - area under the curve

\section{Figures}




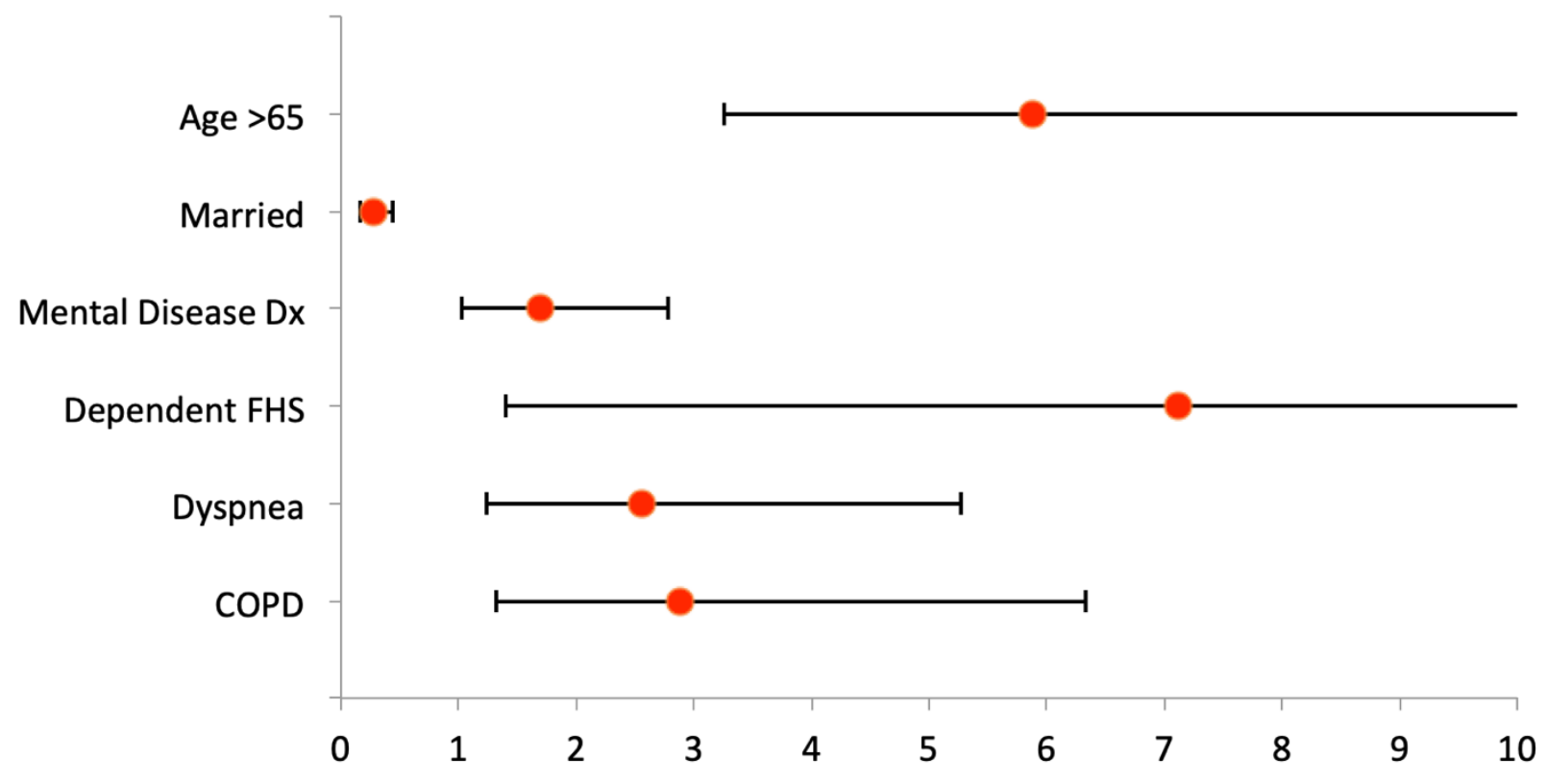

Figure 1. 


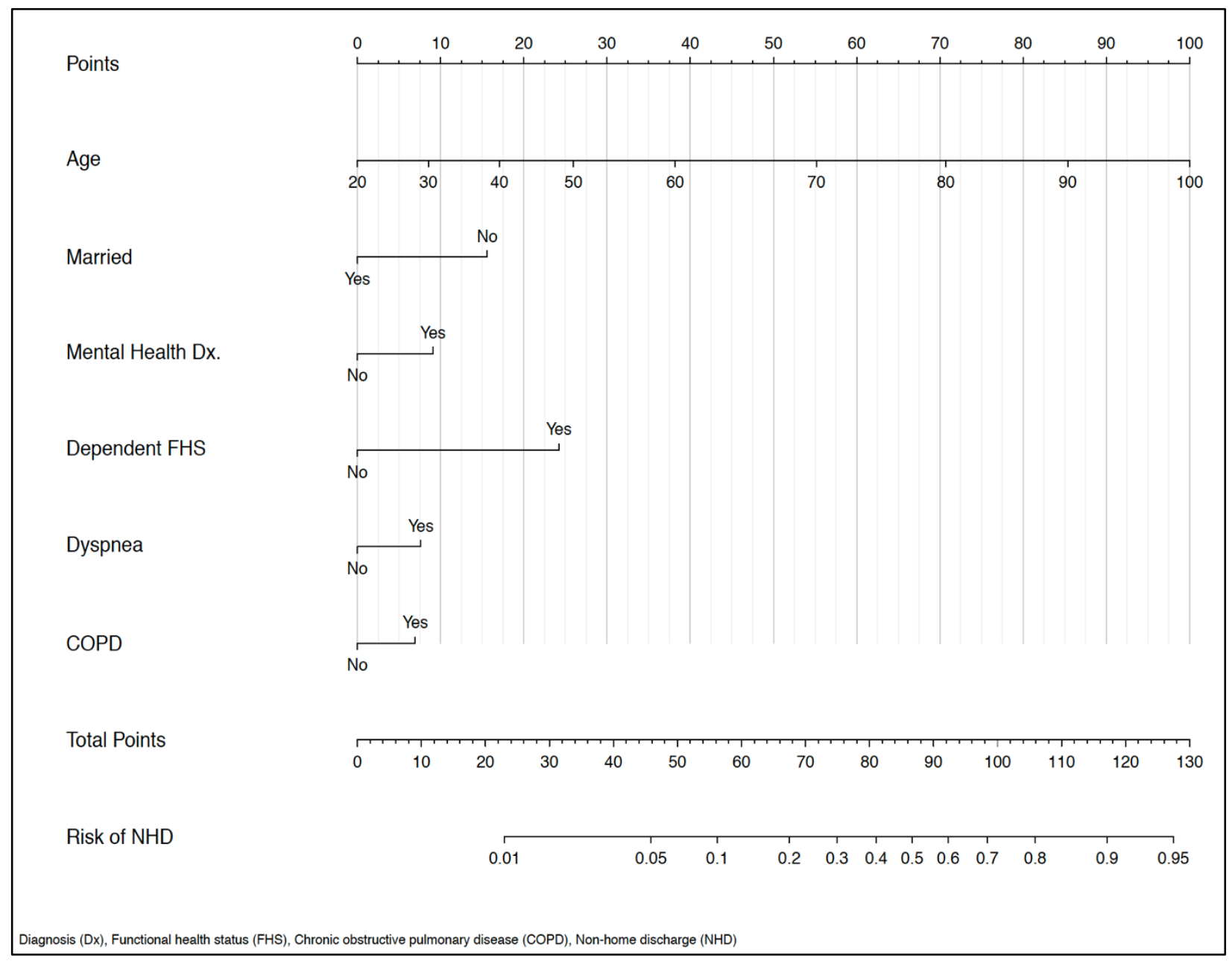

Figure 2. 


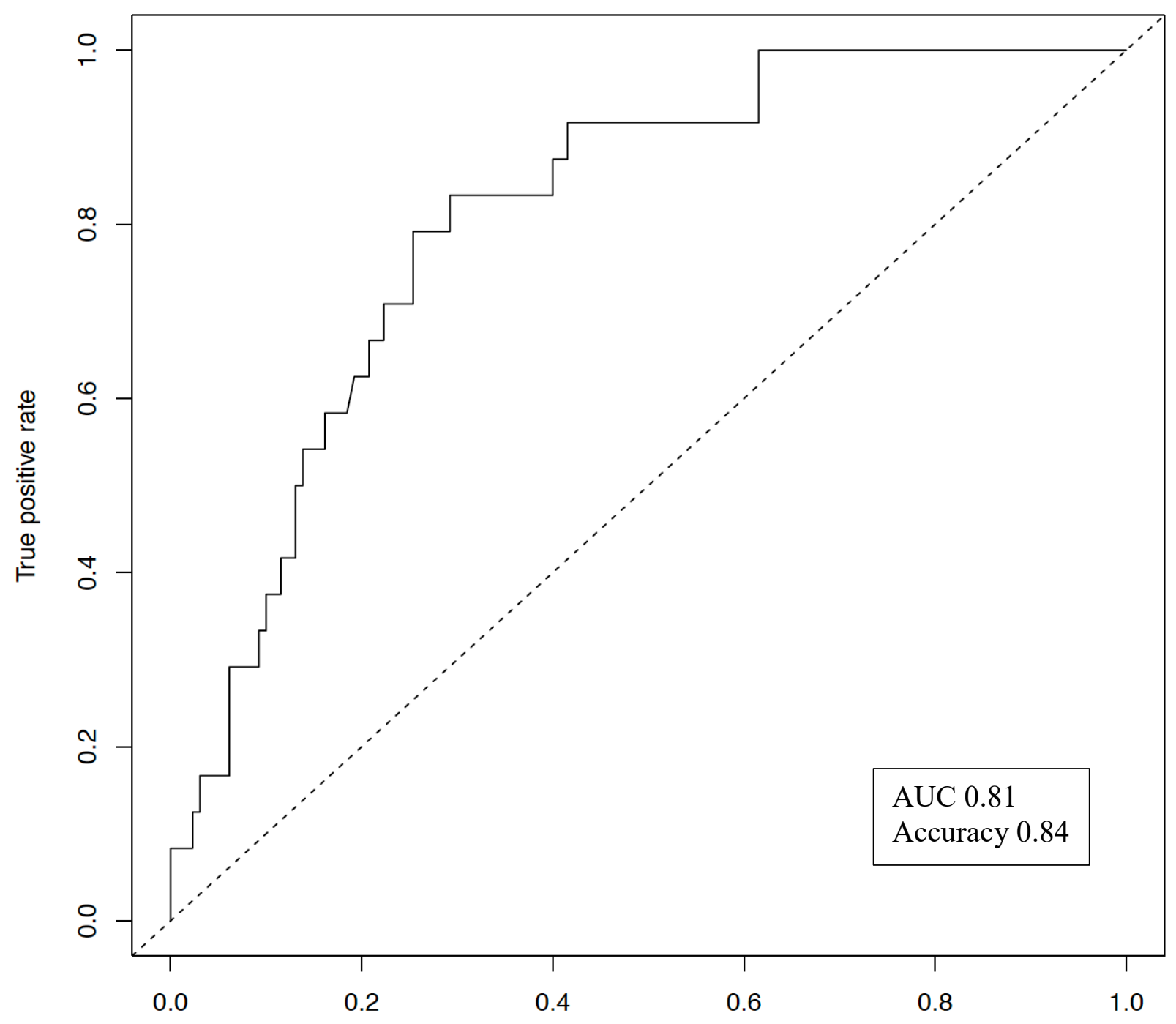

False positive rate

Figure 3 